\title{
Ecos e reverberações: o caminho (oculto) da amizade
}

\author{
Echoes and reverberations: the friendship's (hidden) way \\ José Luiz Foureaux de Souza Júnior \\ Universidade Federal de Ouro Preto - Ouro Preto - Minas Gerais - Brasil
}

\begin{abstract}
Resumo: o presente artigo pretende esboçar um caminho de leitura de um conto de Mário Cláudio: "António Nobre e Alberto de Oliveira". Na abrangência da Literatura Comparada em seu capítulo dedicado à Estética da Recepção a leitura apresenta se desenvolve a partir da articulação de dois conceitos fundamentais: homossociabilidade e homoerotismo. Na perspectiva de leitura a que se circunscreve, este trabalho procura se orientar por um arcabouço teórico que conta com ideias oriundas da Psicanálise (Freud e Lacan) e da Sociologia (Bourdieu). Ainda que eclipsadas, estas ideias contam com o respaldo do raciocínio de Michel Foucault. Sem a pretensão de ser definitivo, dado que se trata de trabalho originado e pesquisa pós-doutoral ainda em andamento, o presente artigo procura desenvolver leitura instigante do conto que aponta para uma releitura da correspondência entre os dois poetas que dão título à narrativa de Mário Cláudio.
\end{abstract}

Palavras-chave: Literatura Portuguesa; Leitura; Mário Cláudio; Homoerotismo; Literatura Comparada

\begin{abstract}
This article aims to outline a reading path of a short story by Mário Cláudio: “António Nobre e Alberto de Oliveira". In the scope of Comparative Literature in the chapter devoted to the Reception Aesthetics reading has developed from the joint of two fundamental concepts: homosociability and homoeroticism. In reading perspective that is limited, this work seeks to be guided by a theoretical framework that has ideas derived from psychoanalysis (Freud and Lacan) and Sociology (Bourdieu). Although eclipsed, these ideas have the support of Michel Foucault reasoning. No claim to be definitive, as it is originated work and post-doctoral research in progress, this article seeks to develop thought-provoking reading of the story that points to a re-reading of the correspondence between the two poets who give title to Mário Cláudio's shor story.
\end{abstract}

Keywords: Portuguese Literature; Reading; Mário Cláudio; Homoeroticism; Comparative Literature

De que é feito um texto? Fragmentos originais, montagens singulares, referências, acidentes, reminiscências, empréstimos voluntários. De que é feita uma pessoa? Migalhas de identificação, imagens incorporadas, traços de caráter assimilados, tudo (se é que se pode dizer assim) formando uma ficção que se chama o eu. (...) A incerteza quanto à paternidade dos livros se conjuga com a fragilidade quanto à permanência e à identidade do eu.

(Michel Schneider, Ladrões de palavras)

Atualmente, ainda persiste a discussão acerca da relação entre estudos culturais e Literatura, per se. Há quem negue a efetividade de tal situação, mas ela é patente. Nesse sentido, os estudos culturais têm aberto uma série de possibilidades metodológicas e, por que não, epistemológicas, para os estudos literários - e vice-versa! Acredito que, no contexto da Literatura
Portuguesa, essa persistência pode ser notada, sem risco de incorrer em erro de avaliação. Parto do pressuposto de que essa interlocução pode ser pensada como uma via de mão dupla e, sem receio de ir "nadar contra a corrente", reivindicarei o direito de dizer que a ideia inicial é: a Literatura pode oferecer muitas possibilidades não apenas para a ampliação, mas, antes, para a manutenção dos 
estudos literários. É claro que, com essa declaração, estou longe de negar as demais possibilidades de articulação.

De certa forma, exerço aqui o direito de me repetir, dado que, como será visto, retomo algumas considerações já desenvolvidas em outras instâncias e publicações já há algum tempo. A repetição - e aqui a inegável sombra freudiana me ampara e protege - se deve, em parte, ao inusitado da proposta: procurar cartas que supostamente ainda existam. Por outro lado, o que aqui apresento vem acrescido de observações e discussões já realizadas em diferentes paragens, margeadas pelo "natural" amadurecimento de ideias e, além disso, apresenta (implicitamente) um plano de trabalho já em desenvolvimento: o projeto de investigação em andamento, no âmbito do estágio de pós-doutoramento que agora realizo em Coimbra, sob a supervisão de Ana Paula Arnaut.

Trata-se da busca de cartas que Alberto de Oliveira teria escrito para António Nobre, durante a vigência de sua relação de amizade. Uma das pedras de toque para a concepção do projeto foi a leitura do conto de Mário Cláudio, "António Nobre e Alberto de Oliveira", publicado em seu livro $O$ triunfo do amor português. Este conto será objeto, aqui, de breve leitura analítica à luz do conceito de pacto homossocial, cunhado por Eve Kosofski Sedgwick, em articulação com o conceito de homoerotismo, utilizado por Jurandir Freire Costa. Isto basta, a meu ver, para respaldar a abordagem de cunho teórico-metodológico, acerca da contribuição do pacto homossocial para a Teoria da Literatura contemporânea e sua eficácia na formulação de uma hermenêutica homoerótica: instrumento mais que necessário na cena dos estudos literários e culturais.

Como o texto que ora se inicia quer, antes de qualquer coisa, exercitar seu direito à leitura, como supõe implicitamente a sua epígrafe, penso que tenho que fazer um preâmbulo para a preparação do terreno em que desejo caminhar. É óbvio que não existe apenas um modo de ler, mas existe uma razão para ler. Essa prática, então, pode estar associada a uma espécie de prazer solitário, como quer Harold Bloom:

Ler bem é um dos grandes prazeres da solidão; ao menos segundo minha experiência, é o mais benéfico dos prazeres. Ler nos conduz à alteridade, seja à nossa própria ou à de nossos amigos, presentes ou futuros. Literatura de ficção é alteridade e, portanto, alivia a solidão. Lemos não apenas porque, na vida real, jamais conheceremos tantas pessoas como através da leitura, mas, também, porque amizades são frágeis, propensas a diminuir em número, a desaparecer, a sucumbir em decorrência da distância, do tempo, das divergências, dos desafetos da vida familiar e amorosa. (BLOOM, 2001, p. 15)
É claro que a amizade é um, dentre os temas presentes no conto de Mário Cláudio, objeto de minhas especulações aqui. As palavras de Bloom fazem pensar sobre o papel da leitura, não apenas enquanto exercício de hedonismo intelectual, mas enquanto prática formadora, uma vez que ela se dá, no contexto presente, no âmbito da universidade. Por isso mesmo, ela parece fazer mais sentido quando se consolida enquanto uma prática e não enquanto uma teoria. Explico-me: não vou tentar convencer meu leitor a aceitar que determinada orientação teórica é mais adequada ou melhor para abordar o conto. De um lado, essa posição se justifica porque não vou tomar a "amizade", enquanto tema, como um valor circunscrito aos "estudos de gênero", em seu sentido mais estrito, mas, sim, em seu sentido mais largo. Da mesma forma que, mesmo implicitamente, se pode perceber nas palavras do narrador do conto, ao comentar a relação entre os dois poetas-personagens, ao afirmar que "não se encontra termo para o que jamais começou, nem princípio para o que brotou terminado." (CLÁUDIO, 2004, p. 236)

Note-se que a amizade a que me refiro aqui aparece explicitamente tematizada no conto de Mário Cláudio; daí a possibilidade de se vislumbrar, no horizonte de expectativas da leitura dos textos em questão, uma possível e consistente referência aos "estudos de gênero":

A pretensão é (...) entender o gênero como constituinte da identidade dos sujeitos (...) tendo identidades plurais, múltiplas; identidades que se transformam, que não são fixas ou permanentes, que podem, até mesmo, ser contraditórias. (...) O gênero institui a identidade do sujeito (assim como a etnia, a classe, ou a nacionalidade) (...) algo que transcende o mero desempenho de papéis (...). (LOURO, 1999, p. 24-25)

Assim, ao ler e interpretar, deve-se procurar explicitar o que está implícito na obra analisada; perceber e articular o que pode e deve ser explicitado. Não se pode esquecer que o exercício da leitura é, entre outras coisas, uma espécie de fortalecimento do ego, uma tomada de consciência dos autênticos interesses do ego, ainda que essa autenticidade, em si mesmo, seja questionável. O prazer da leitura é pessoal e não social, como diz Bloom. Pesando e medindo bem as palavras do crítico, pode-se concordar com ele, quando afirma:

Hoje em dia, a maneira como lemos depende, em parte, da distância em que nos encontramos das universidades, onde a leitura não é ensinada como algo que proporciona prazer, isto é, segundo os significados mais profundos da estética do prazer (...). Se resta à crítica literária, hoje em dia, alguma função, esta será a de dirigir-se ao leitor solitário, que lê por iniciativa própria, e não segundo interesses que, supostamente, transcendam o ser. (Idem, p. 18-19.) 
Adiante, então, com essa prática solitária!

Os ecos e as reverberações, citados no título deste artigo, fazem referência ao projeto de investigação, no âmbito do qual se circunscreve. É nas tais cartas trocadas entre os dois poetas - aqui, personagens da ficção de Mário Cláudio, a confundir o leitor menos avisado - que pretendo estabelecer os elos de encadeamento da amizade entre os dois. Isto, porém, vai ficar aqui, apenas a título de insinuação. No entanto, os mesmos elementos referidos ecos e reverberações - satisfazem meu desejo, enquanto elos de uma corrente que envolve os dois missivistas num universo ficcional que não deixa de apontar para sua biografia.

Trata-se de exercício, mais que criativo, que resulta numa espécie de certa especularidade da/na tradição que abre sua caixa de Pandora - porta da criatividade literária -, no sentido de conduzir o leitor pelo olhar "enviesado" de um discurso silenciado pela própria tradição. Isto, num segundo momento, poder-se-ia identificar como um discurso homofóbico. Isso vai constituir o que chamo de "esquecimento" da crítica, quando não ousa ultrapassar os limites de seu próprio absolutismo, ainda que esclarecido. A epígrafe, na tentativa de dar um caminho possível para questionar a constituição de um sujeito, o autor de um livro, conjuga pessoa e texto, numa série de possibilidades que, sintomaticamente, não incorpora a que mais me interessa: o escrever sobre, tal como nas cartas. De certa forma, a partir dessa chave de leitura, esquecer também é um processo que pode contribuir para a concepção de uma obra de arte. O sujeito que escreve é também um produtor de conhecimento, pois é necessário ter "elaborado" algo sobre o que escrever. Assim não fosse, Freud não teria tido tanto trabalho para explanar sobre os lapsos e os chistes que tanto apavoram um inconsciente deslumbrado com as suas próprias possibilidades: uma espécie de narciso psíquico.

A leitura das obras de Mário Cláudio é prática que dá coceira no cérebro, fica longe de ser uma atividade envolta em qualquer sossego. Percorrer seu texto é procurar a solução de um enigma que, assim como a do mito, tinha um único objetivo: devorar. A escrita de Mário Cláudio devora a atenção do leitor e esgota as possibilidades mais rasteiras de leitura, pela fineza no trato com as palavras, a delicadeza na pintura das figuras humanas e na sutileza sagaz com que compõe seus enredos. Os períodos são longos e o fôlego do leitor titubeia, mas em pleno gozo estético. Seu estilo, ímpar, é consolidado pela erudição do vocabulário e pela criação de imagens que transformam o discurso ficcional num exercício plástico que, induz o leitor a perceber as suas sugestões. Mais do que dizer, pergunta, como Carlos Drummond de Andrade: "Trouxeste a chave?". Um exemplo disso, pode-se encontrar, no conto, quando o narrador diz a respeito da amizade entre os dois poetas-personagens: “(...) mantêmse os selectivos camaradas, volvendo uma longa olhadela lá do cimo ao que consideram, não sem uma ponta de apiedado desprezo, resíduo lusitano da grande humanidade torturada". (CLÁUDIO, 2004, p. 230)

Mesmo sem ser explícito, o exemplo ilustra as características do "estilo" de Mário Claudio, o que ajuda a tornar mais instigante a presente proposta de leitura de um de seus textos. Neles, o autor desenvolve discurso marcado pela imprecisão - e nisso não há sentido pejorativo algum, pelo contrário! Nada é exatamente aquilo que parece ser e até a totalidade fica sujeita à condição de fragmento. Com os fragmentos de nosso tempo é que Mário Cláudio constrói seu texto como um caleidoscópio. Sem pudor falso, o escritor invade áreas distintas do fazer artístico e delas tira o motivo para a construção da sua escrita. Em outras palavras, "roubando corpos" de outras formas de arte, Mário Cláudio os reconstrói, oferecendo em troca um "corpo em linguagem". Forma diferente não tem o texto do conto, motivo desta análise.

Ao descortinar, pelo menos no delírio controlado da ficção, o mundo que rodeia e envolve dois outros poetas portugueses - António Nobre e Aberto de Oliveira - Mário Cláudio escreve um conto que está longe corresponder ipsis literis ao modelo convencional e canonizado de narrativa curta. Ele o faz, utilizando de instrumentos igualmente escritos, as cartas de António Nobre e os relatos biográficos dos dois poetas. Pode-se dizer que para usar terminologia mais "moderna" - o contista faz aqui uma pirataria. Um exercício de "pilhagem", quando se "apropria" das cartas e das biografias sem se deixar dominar pelo risco fácil de repetir o que já foi dito. Com o tempo, fica cada vez mais difícil "assustar-se", ainda que surpreender-se seja sempre uma reação plausível e instigante. Diferentemente das cartas de António Nobre, o tom do texto de Mário Cláudio que, a partir daquele se constrói, está longe de ser um exercício desvalido de queixas, marcada pelo excesso de reticências e de exclamações e dominada por um tom declaradamente "interjetivo". Pode-se dizer que no delicado apreço demonstrado pelo narrador, há quase uma frieza objetiva na apresentação de passagens, momentos, sensações, pensamentos:

Entre António e Alberto forma-se a invisível corrente, através da qual transitam crípticas imagens de cumplicidade, e de ternura, que os restantes em absoluto incompreendem, se bem que as deduzam dessa espécie de perturbação que impregna o ar dos sótãos. (CLÁUDIO, 2004, p. 229)

Descrição (até) poética, é verdade. E já aqui pressente-se, nas entrelinhas do narrador a referência implícita ao afeto homoerótico explícito e aceito. Essas 
duas caraterísticas se referem aos dois protagonistas da relação, seja dito. De fato no momento em que a historia deles acontece, como apresentado no conto é implícito o pressuposto de que a sodomia e/ou a pederastia é que eram praticas condenáveis. A relação afetiva dos dois está, até prova em contrário, longe disso. De mais a mais, o que menos interessaria é validar ou não esta hipótese, pouco acrescentaria ao exercício sedutor da leitura. No entanto, negar a plausibilidade do afeto, é erro crasso:

Planeiam distintas coisas em privado desde a travessia do mítico veleiro, capaz de aportar às praias clássicas do golfo de Nápoles, até ao inquebrantável pacto de sangue que enfrente o fatalismo do casamento, ao qual atribuem de resto a virtude de sanear a excessiva carga da atmosfera que respiram. (Idem, p. 230)

Veja como soa simultaneamente ambíguo e delicado dizer que eles procuravam "sanear a excessiva carga da atmosfera que respiram". A meu ver, mais uma vez, consolida-se o carater homossocial do pacto que selam, nas diversas formas que vai tomando ao longo da vida dos dois protagonistas do conto. Mas o narrador é um fingidor hábil, por isso há que ter em conta certa indeterminação que acaba por amarrar a escritura de Nobre - dado que as cartas de Alberto de Oliveira em sua praticamente absoluta totalidade, são desconhecidas do público - à escritura de Mário Cláudio, transformando a escrita do conto numa espécie de ficcionalização da biografia ou seu oposto. Depene do desejo do leitor. De fato, o narrador acompanha de perto suas criaturas, desvelando o seu próprio fazer literário que, como uma espécie de metaficção, inscreveu também a ficção da escrita, como na seguinte passagem:

De Alberto de Oliveira permaneceria o discurso da contenção, e do projecto, tratando das folhas de um volumezinho de versos, fabricadas de papel ridiculamente demolhado em chá, com vista a reproduzirem a aparência, e o toque, das páginas de um velho saltério, e mais as descrições dos encontros providenciais com quanto áulico andasse de roda de El-Rei, a praticar de banalidades numa construção gramatical que se pretendia francesa, esforçando-se por não se distrair de pronunciar pequeno, conforme julgava dever ser, com um i, e acrescentando, "Lá gostei muito dos seus poemas", "Faz-me grande impressão o seu talento", "Venho de folhear uma coisa extraordinária do nosso Sabugosa." (Idem, p. 237)

A referência à poesia de Alberto de Oliveira, em certa medida, corrobora o que antes vinha dito. Além disso, abre a possibilidade de especular sobre a existência das cartas que ele teria escrito em respostas àquelas enviadas por António Nobre. De fato, na edição da correspondência de António Nobre, organizada por Guilherme de Castilho, em nota explicativa de número 1 , comentando a carta, nesta edição, que leva o número 72 - a famigerada carta que sela o rompimento da amizade entre os dois e revela o desejo de destruir o "diário" expresso por Nobre-, o editor reproduz uma carta de Aberto de Oliveira. (CASTILHO, 1982, p. 524-525) ${ }^{1}$

Isto posto, percebe-se, ao longo do texto, expressões e palavras utilizadas pelo narrador, que corroboram a perspectiva homoerótica a que se circunscreve a relação afetiva dos dois poetas: "impossível amor", (p. 227-228); "a ardência do lume que os encadeia", (p.229); "os seletivos camaradas", (p. 230); "pungência do sentimento que os une", (p.231); "um drama idílico", (p. 232); "pacto que celebram", (p.233); "ágape de ambrósia evanescente", (p. 234); "desgrenhados afetos", (p. 236); entre outras. Em todas elas, percebe-se, claramente, a clave do homoerotismo, transfigurada em metáforas e metonímias que remetem, sempre e cumulativamente, ao contexto da amizade entre os dois poetas. As duas últimas, particularmente, me interessam de perto. Elas me levam a pontuar o suporte conceitual de que me sirvo que, entre outras referências leva a Jurandir Freire Costa, em seu A inocência e o vício.

É plausível diferenciar os dois termos - homossexualismo/homoerotismo - aqui em jogo, ainda que implicitamente. O privilégio recai, logicamente sobre o segundo, dado que este contribui para a discussão do que se conhece como ética da vida privada. É esta, seguramente, a que abrange a relação que é tomada como mote do conto de Mário Cláudio. Há que e manter certa preocupação com o preservar do modo de viver da tradição cultural a que o sujeito se circunscreve. Neste sentido, a Psicanálise contribui e muito. Esse raciocínio se mantém respaldado pela seguinte questão: qual o direito da sociedade, grupos ou indivíduos, de obrigar quem quer que seja a ser social e moralmente identificado em sua aparência pública por suas preferências eróticas? Daí, a necessidade da diferenciação conceitual. Há dois pressupostos: a incidência do preconceito sexual sobre a conduta dos sujeitos que agem e sentem de modo "diferente" e o uso que se faz das noções de "perversão" ou "neurose" quando aplicadas ao fenômeno da atração erótica entre pessoas do mesmo sexo biológico. Do ponto de vista da sexualidade (física) nada há o que questionar sobre a relação entre os dois poetas-personagens. De fato, isso pouco me interessa. Por outro lado, do ponto de vista

\footnotetext{
Permito-me uma digressão: não seria mais que interessante "descobrir" estas cartas ou, pelo menos, parte delas? A possibilidade, ainda que virtual, existe. Em várias cartas de António Nobre há indícios disso. Se elas existem, onde estariam? Se existem e fosse localizado seu paradeiro, seria possível consultá-las? Será que o portador deste acervo autorizaria sua publicação, como complemento àquelas escritas pelo António Nobre? Veredas da crítica...
} 
da afetividade, não se pode admitir visão preconceituosa, a partir de argumentos falaciosos.

A teorização acerca do homoerotismo não é assim tão recente. Ela retoma o que foi criado por F. KarshHaack, em 1911, e utilizado neste mesmo ano por Sandor Ferenczi, em trabalho sobre o tema. Não se trata, evidentemente, de apenas rebatizar moralmente a chamada "homossexualidade". Ferenczi, com o termo, teve justamente a intenção de criticar o saber psicanalítico da época, fenômeno e percebido como "atração pelo mesmo sexo". Freud, em seu Três ensaios sobre a teoria da sexualidade, de 1920, avalizou o emprego do termo. Quando se emprega a palavra "homossexualidade", inevitavelmente vêm ao pensamento duas coisas: ou que o "homossexualismo" é uma condição natural, um tipo específico de sexualidade comum a certos indivíduos, em qualquer período histórico ou circunstância cultural, ou então que se trata de uma "condição psicológica" igualmente universal e típica de certos sujeitos.

Este uso alude ao que é comumente designado como "homossexualidade", mas procura evitar que o leitor moderno, preso a hábitos cristalizados, desse o sentido de "homossexualidade" a quaisquer práticas eróticas entre indivíduos do mesmo sexo biológico. Em se tratando de uso de termos, note-se a já referida sutileza do autortambém na passagem seguinte que bem demonstra e ilustra o raciocínio até aqui desenvolvido:

Quando cuida Nobre de viver sem vigilâncias nocivas, nem escolásticos impedimentos, a amizade que entre ele e Alberto de Oliveira foi gloriosamente crescendo, é em Leça da Palmeira que pensa, não como cenário do desenrolar de um drama idílico apenas, mas como substância que deverão dividir em fracções iguais dois poetas, praticando do amor de um Portugal a que os pintores não são capazes de aceder. Alugam uma casinha térrea a um desses velhos pescadores barbudos, conhecido pelos locais pitorescamente como João Moca, e para lá transplantam livros e canhenhos, toilettes completas e material de fumo, chapéus e adereços, como se fossem iniciar sem limite fixo uma equilibrada existência dual. (CLÁUDIO, 2004, p. 232 - grifos meus $)^{2}$

Percebe-se aqui a coerência do uso do termo e a abordagem que introdutoriamente apresento aqui. Acrescente-se que o erotismo aqui está muito longe de ser reduzido práticas, experiências, reatos e relações da ordem da sexualidade (apenas). Para além deste perímetro, se acompanhar Foucault ainda é atitude acertada, como penso que é, o horizonte é mais largo, fazendo com que António Nobre e Alberto de Oliveira, sobretudo no

\footnotetext{
2 Esta passagem me faz lembrar de um conto de Machado de Assis, "Pílades e Orestes", em que igual matéria, em similar sintonia cultural, é objeto da narrativa curta.
}

conto de Mário Cláudio, sejam considerados sujeitos desta instância da vida privada, ainda que ficcionalmente tratada.

Nesta direção, cumpre ressaltar que, ao observar a linha do tempo, no que diz respeito ao desenvolvimento desses conceitos, percebe-se que, pelo contraste de culturas diversas, como a greco-romana, por exemplo, o que se acredita "do jeito que sempre foi" é axioma que não tem nenhuma sustentação técnica plausível e, ainda menos, fundamentos científicos, como se supõe. A pederastia grega e o "homossexualismo moderno" são duas formas absolutamente diferentes de se descrever, sentir e avaliar moralmente as relações ou atração erótica entre pessoas do mesmo sexo. Por isso mesmo, penso na plausibilidade da abordagem aqui adotada, dado que os poetas-personagens agem e sente, na ficção, de maneira a sustentar as hipóteses de leitura aqui apresentada, pelo menos, e o que nos faz perceber a "voz" do narrador.

Para concluir esta digressão, a cultura em que vivemos - contexto no qual se articula a leitura do conto é, majoritariamente, heteroerótica, o que não significa que outros modos de ordenação do desejo não possam existir. Isto não quer dizer que o conto se proponha a sustentar uma proposta para a reforma da sexualidade. É impossível escolher a sexualidade, assim como não se escolhe a língua materna. No entanto, é possível redescrever moral, social e ficcionalmente, as articulações que o desejo impõe e faz expressar pela linguagem, no caso, ficcional. Afinal de contas, a troca de vocabulário leva, quase automaticamente, à troca de problemas. Com essa troca, algumas coisas da realidade, que antes pareciam absolutamente importantes, passam a não ter mais importância.

De certa forma, o conto de Mário Cláudio pode ser lido como uma narrativa incompleta, projeto falhado porque desejou a inteireza. Justamente no bojo desse mesmo desejo, por causa dele, o conto acaba por conseguir certa "completude", no que diz respeito à expressão ficcional de um afeto pouco compreendido, quando de sua ocorrência:

Se conhecerem-se, e amarem-se, não como é patente obra de um momento, atribua-se à época, tão pronta a conceder o que nega, e a descobrir o que escamoteia, a diuturnidade do afecto, votado a labirintos onde se entra, e donde se sai, quando não se está certo, nem seguro, de pretender alcançar o centro. (CLÁUDIO, 2004, p. 229)

Esta passagem, em sua dicção ficcional, explicita, na minha opinião, uma das melhores "descrições" do homoerotismo na história dos dois poetas. Por isso mesmo, penso que a ideia e pacto homossocial - no diapasão proposto pela harmoniosa elaboração de Eve Kosofski Sedgwick - é eficaz, eficiente e efetiva, na leitura da 
narrativa ficcional da amizade dos poetas. O conto é escrito a partir de uma impossibilidade da escritura, ado que não se tem conhecimento das cartas escritas por Alberto de Oliveira, dirigidas a António Nobre, exceção feita à carta - a que registra indelevelmente o rompimento da amizade - que leva o número 72, na edição de Guilherme de Castilho, da correspondência do segundo. ${ }^{3}$

Pode-se concluir que a escrita do conto realiza uma espécie de travessia, aqui, a travessia, pelo espaço da página em branco, em direção à posse de um corpo: o corpo da própria escrita. Isto por conta da ausência das "respostas" de Alberto de Oliveira às cartas de António Nobre. Note-se que, a tomar como procedente a ideia de travessia, esta se faz por intuição, implicitamente, muito mais pela leitura que, da escrita do conto, se faz. Tal travessia se explicita num discurso eroticamente trabalhado - como, de resto, o foi seu similar, no que se refere à amizade descrita em cartas entre os dois poetaspersonagens. Tal assertiva se sustenta ainda que no texto do conto não haja, de maneira explícita, referência ou pontuação direta a estas mesmas cartas. A letra do contista, na voz de seu narrador, é o risco na página, a tomada de posse de um território virgem, definição de uma nova geografia que ganha concretude significante e que restitui à escrita a condição de grafia do humano.

Nesse caso, dadas as circunstâncias da apresentação e caracterização da relação de amizade entre as duas personagens, não vejo como não admitir a efetividade do já referido "desejo homossocial", cujo princípio homônimo estabelece as bases de um compromisso que envolve não apenas o comportamento social, mas os desejos individuais de cada uma delas. Evidentemente, numa direção outra, em relação ao poema, o conto aponta e reafirma a plausibilidade da leitura operacionalizada pelo princípio da homossociabilidade, no sentido estabelecido por Eve Kosofsky Sedgwick:

\begin{abstract}
"Male homosocial": the phrase in the title of this study is intended to mark both discriminations and paradoxes. "Homosocial desire", to begin with, is a kind of oxymoron. "Homosocial" is a Word occasionally used in history and social sciences, where it describes social bonds between persons of the same sex; it is a neologism, obviously meant to be distinguished from "homosexual". In fact, it is applied to such activities as "male bonding," which may, as in our society, be characterized by intense homophobia, fear and hatred of homosexuality. (SEDGWICK, 1985, p. 1)
\end{abstract}

A conceituação da autora corrobora discussões de cunho teórico, implícitas na leitura do conto de Mário

\footnotetext{
3 Existe o registro de uma outra carta, depositada na Biblioteca Municipal Florbela Espanca, em Matosinhos, cujo conteúdo ainda desconheço.
}

Cláudio. Isso se dá porque a ideia de homossociabilidade - e, derivadamente, o pacto que a partir dessa ideia é possível estabelecer - articula-se, psicanaliticamente, à ideia de desejo, no quadrante em que, evidentemente Freud e Lacan se encontram como bastiões. Num segundo momento, Pierre Bourdieu, quando se refere à "dominação masculina" ajuda na sustentação da hipótese de certa submissão de Alberto de Oliveira a António Nobre, via sedução que este exerce.

Evidentemente, afirmar que o fazia de maneira deliberada é passo muito grande que pode levar a queda. No entanto, a sedução que a figura de Nobre exerce indiscriminadamente - haja vista, por exemplo, sua opção por vivenciar o que é conhecido como "idade de ferro", nas palavras do próprio Alberto de Oliveira - não eixa dúvidas sobre esse aspecto sedutor que pode ser percebido, também implicitamente, nas sutilezas descritivas que o autor do conto executa ao longo da narrativa.

Por fim, se acedermos à ideia de "cuidado" e da "vontade de saber", Foucault vai reforçar outro argumento implícito: o de quê, de fato, no conto - eu ouso afirmar que a correspondência deixa isso muito claro - não está em jogo a pertinência ou não de uma relação física entre os dois poetas, da/na perspectiva da sexualidade. Ao contrário, seu afeto ultrapassa a barreira do preconceito, na leitura que do conto se pode fazer, dado que, na perspectiva do próprio pensamento de Foucault, não se criminaliza o afeto, mas a sodomia. Outros pensadores vão pelo mesmo caminho. Fico com os aqui referidos.

Há que destacar o traço poético (no sentido etimológico do termo) que marca os conceitos vinculados à leitura que aqui apresento. Esse traço faz com que sua pertinência seja consolidada na leitura do conto, provocando uma vinculação da ordem do hermenêutico. É nessa perspectiva que se deve tomar o texto aqui lido. Há, nele, elementos que confirmam a potencialidade hermenêutica do conceito de homossociabilidade e, por isso mesmo, abrem novas possibilidades de interpretação do conto, sem necessariamente torcer-lhe a natureza; muito antes, aumentando consideravelmente a espessura de sua fortuna crítica, atualizando - como queria Jauss sempre e mais a obra lida.

Complementando esse comentário acerca do traço poético que marca o uso de termos como "homoerotismo", há que se destacar a profunda delicadeza do autor do conto em passagens contundentes de sua narrativa. Em contraposição à "boêmia louca" (CLÁUDIO, 2004, p.227) que identifica o ambiente um tanto esperado em que tem início a amizade entre os dois poetas-personagens, tem lugar "um drama idílico" (Idem, p. 232), que se desenvolve até um desfecho quase trágico, tratado com sensibilidade e carinho pelo narrador: 
Está em Carreiros na Foz do Douro, e na residência do irmão, com os olhos mais escancarados do que nunca, absorvendo a cintilação do Atlântico, e de mãos juntas como quem espera que lhe venham ensinar uma oração, há séculos esquecida, e que confunde de vez em quando com um soneto rejeitado. Ao entrar Augusto, já o sol declinou, e suspenderam-se os espasmos que the provocam estremeções do esqueleto, e esplendidamente se sente, e como se tivesse acabado de nascer, concentrando-se no labor da aranhazinha que, animada pelo calor, afanosamente segrega o fio. É Alberto quem em lugar do mano dedicado se aproxima, e pede-lhe António num murmúrio que o abrace, e ao achar-se apertado pelo companheiro de sempre, consente em que a cabeça se lhe descaia, de infinito êxtase, sobre o ombro daquele que jamais o traiu. (Idem, p. 243) ${ }^{4}$

Nos enrijecidos padrões de comportamento que uma experiência inusitada provoca em dois estudantes em Coimbra, no final do século XIX, o contrato homossocial é uma inegável articulação de desejos e discursos que provocam no leitor uma espécie de espanto que leva à percepção (afinal, uma forma de conhecimento, como queria Platão!) de nuances que a dicção literária é capaz de provocar num conjunto de elementos corriqueiros como as palavras. Estas constroem discursos que vão levar o leitor a mundos outros em que as aparentes verdades eternas se desfazem, pela ação de um olhar atento e, por que não, enviesado, apontando para detalhes outros, igualmente inusitados. Assim, trata-se, num plano mais geral, de um espanto que poderia ser chamado de o "paradoxo da doxa", como anunciado por Pierre Bourdieu:

(...) o fato de que a ordem do mundo, tal como está, com seus sentidos únicos e seus sentidos proibidos, em sentido próprio ou figurado, suas obrigações e suas sanções, seja grosso modo respeitada, que não haja um maior número de transgressões ou subversões, delitos e "loucuras". (BOURDIEU, 1999, p. 7)

$\mathrm{O}$ autor, tratando de aspectos e representações do que se conhece por "dominação masculina", faz-se pertinente ao ser citado neste trabalho, uma vez que esse "masculino" é o objeto construído pela linguagem no texto do conto, palimpsesto dos outros textos que o compõem. Pode-se perceber isso, por exemplo em passagens do conto com esta: "O jogo do mais aliciante magnetismo" (CLÁUDIO, 2004, p. 229), ou ainda, quando da partida de António Nobre, deixando Alberto de Oliveira no cais:

Mas era em Alberto, nesse que ficara, minúsculo e sem defesa, ao ser observado do cimo da amurada, especado no extenso cais da beira-Tejo, que lançava âncora o pensamento do viajante, e nada havia que não lhe dedicasse, do que ia sentindo, e do que ia acontecendo, mágoas e saudades, ímpetos e planos, medos e desconhecimentos, risos e lágrimas, porque era aquele o seu deus particular, a quem tudo se oferecia, a quem tudo se sacrificava. (Idem, ibidem - grifo meu)

Numa relação dialética consigo próprio - seja na perspectiva do erotismo, seja na perspectiva do comportamento social - o masculino questiona e reafirma a instabilidade das chamadas "verdades eternas, a doxa. Os paradoxos constitutivos que mantêm esse masculino vivo, experimentando uma crise, não levam necessariamente à conclusão de que um modelo prevalece, mas, ao contrário, modelos são construídos à medida que olhares se enviesem, construindo caminhos outros de direcionamento da leitura.

Como acontece no conto, pode-se pensar num certo exercício de dominação que, por um momento, parece natural. A fascinação causada por António Nobre sobre Alberto de Oliveira - implicitamente, aqui, revelada pelas cartas do primeiro - aparece como instrumento de veiculação de um contrato homossocial, responsável pelo desvelamento de relações não-superficiais, que ultrapassam a estreiteza dos padrões sociais vigentes. Isso leva a concordar com o que diz, mais uma vez, Pierre Bourdieu:

(...) o que é ainda mais surpreendente, que a ordem estabelecida, com suas relações de dominação, seus direitos e suas imunidades, seus privilégios e suas injustiças, salvo uns poucos acidentes históricos, perpetue-se apesar de tudo tão facilmente, e que condições de existência das mais intoleráveis possam permanentemente ser vistas como aceitáveis ou até mesmo como naturais. (Idem, ibidem)

Mário Cláudio oferece, aqui, um exemplo que a Literatura Portuguesa produziu, a partir dos quais o exercício da leitura pode ser realizado sob a perspectiva de uma hermenêutica do homossocial. Enquanto prática de recepção de textos, essa leitura amplia os horizontes de expectativas da própria obra do escritor, atualizando essa mesma obra, numa visada outra que sai do lugar comum, ousando voos mais amplos e abrangentes:

Que lhe ofereça António, e num poema lindo ${ }^{5}$, o título de "condezinho Tolstoi" não esclarece sobre com que diferentes primores poderão no futuro homenagear-se entre si, razão por que melhor se tornará remeter-se ele, Alberto, à reserva calculada donde é fácil assistir ao progresso daquilo que, não sendo amizade, só com a mais elevada essência afectiva, perigosa de se nomear, se deparará em condições de coincidir. (CLÁUDIO, 2004, p. 231 - grifos meus)

\footnotetext{
4 Esta passagem me lembra a narrativa lírica de Caio Fernando Abreu. $\mathrm{Na}$ sua contundência, quase agressiva, o escritor brasileiro, em muitas imagens, se aproxima do poeta português, e vive-versa, apesar das óbvias diferenças, distância cronológica, de gênero e cultural.

5 Qual seria este poema? Talvez na edição das cartas haja alguma referência que possa iluminar o caminho a encontrar este poema.
} 
A crítica que se constrói a partir dessa leitura pode causar, no próprio leitor, a impressão de estar, finalmente, diante da verdade sobre a constante mescla de sofrimento banal e humor trágico que caracteriza a existência humana. Ainda que essa verdade seja sempre revisitada, reconstruída, modificada.

\section{Referências}

ACHTER, Erik Adolf Van. On the nature of the [Portuguese] short story: a poetics of intimacy. 2010. $323 \mathrm{f}$. Tese (Doutorado em Letras) - Departamento de Letras, Universiteit Utrecht, Utrecht: 2010.

AUBRIT, Jean-Pierre. Le conte et la nouvelle. Paris: Armand Colin, 1997.

BARTHES, Roland. Aula. São Paulo: Cultrix, 1989.

BAUDRILlARD, Jean. Da sedução. Trad. Tânia Pellegrini. Campinas: Papirus, 1991

BLOOM, Harold. A angústia da influência: uma teoria da poesia. Rio de Janeiro: Imago, 1991

BLOOM, Harold. Como e porque ler. Trad. José Roberto O'Shea. Rio de Janeiro: Objetiva, 2001.

BOURDIEU, Pierre. A dominação masculina. Trad. Maria Helena Kúhner. Rio de Janeiro: Bertrand do Brasil, 1999.

BRANDÃO, Junito de Souza. Mitologia grega. 3. ed. Petrópolis: Vozes, 1989.

CASTILHO, Guilherme de. António Nobre: correspondência. Lisboa: Imprensa Nacional: Casa da moeda, 1952.

CASTRO Laura. Mário Cláudio: 30 anos de trabalho literário (1969-1999). Porto: Cooperativa Árvore, 1999.

CLÁUDIO, Mário. Triunfo do amor português. Lisboa: Dom Quixote, 2004.

COELHO, Jacinto do Prado (Coord.). Dicionário de literatura portuguesa, brasileira, galega, africana. Porto: Figueirinhas, s/d.

COSTA, Jurandir Freire. A inocência e o vício: estudos sobre o homoerotismo. Rio de Janeiro: Relume-Dumará, 1992.

COSTA, Jurandir Freire. A Ética e o espelho da cultura. Rio de Janeiro: Rocco, 1994.

COSTA, Jurandir Freire. A face e o verso: estudos sobre o homoerotismo II. São Paulo: Escuta, 1995.

FOUCAULT, Michel. História da sexualidade I: a vontade de saber. Trad. de Maria Theresa Costa Albuquerque e José Augusto Guilhon Albuquerque. Rio de Janeiro: Graal, 1988.

FOUCAULT, Michel. História da sexualidade III: o cuidado de si. Trad. de Maria Theresa Costa Albuquerque e José Augusto Guilhon Albuquerque. Rio de Janeiro: Graal, 1985.

FRÖHLICHER, Peter; GÜNTERT, Georges (Eds.). Teoría e interpretación del cuento. Bern: Frankfurt: Peter Lang, 1995.

GOMES, Graça Joana da Cruz. História, ficção e transgressões em "Triunfo do amor português" de Mário Cláudio. 2009. $134 \mathrm{f}$. Dissertação (Mestrado em Letras) - Faculdade de Letras, Universidade de Coimbra, Coimbra, 2009.

GOTLIB, Nádia Battella. Teoria do Conto. São Paulo: Ática, 1987. GOULART, Rosa Maria. O conto: da literatura à teoria literária. Forma Breve - revista de literatura, Aveiro, n. 1, p. 9-16, 2003.
HUTCHEON, Linda. Poética do pós-modernismo: história, teoria e ficção. Trad. de Ricardo Cruz. Rio de Janeiro: Imago, 1991.

IMBERT, Enrique Anderson. Teoría y técnica del cuento. Barcelona: Ariel, 1991.

ISER, Wolfgang. $O$ ato de leitura: uma teoria do efeito estético. São Paulo: 34, 1996-1999. 2 v.

ISER, Wolfgang. O fictício e o imaginário. Rio de Janeiro: UERJ, 1996.

JAUSS, Hans Robert. A estética da recepção: colocações gerais. In: COSTA LIMA, Luiz (Org.). A literatura e o leitor. Rio de Janeiro: Paz e Terra, 1979, p. 43-61.

JAUSS, Hans Robert. A história da literatura como provocação à teoria literária. Trad. De Sérgio Tellaroli. São Paulo: Ática, 1994.

KIEFER, Charles. A poética do conto de Poe a Borges - um passeio pelo gênero. São Paulo: Leya, 2011.

LETRIA, José Jorge. Conversas com letras - entrevistas com escritores. Lisboa: O Escritor, 1994.

LOHAFER, Susan; LOUNSBERRY, Barbara; ROHRBERGER, Mary; PETT, Stephen; FEDDERSEN, Rick (Eds.). The tales we tell: perspectives on the short story. Westport: Greenwood Press, 1998.

LOPES, Óscar; MARINHO, Maria de Fátima (Eds.). História da literatura portuguesa. Lisboa: Alfa, 2002.

LOPES, Óscar; SARAIVA, António José. História da literatura portuguesa. Porto: Porto Editora, 2005.

LOURENCY, Eduardo. O canto do signo: existência e literatura (1957-1993). Lisboa: Editorial Presença, 1994.

LOURO, Guacira Lopes. Gênero, sexualidade e educação: uma perspectiva pós-estruturalista. Petrópolis: Vozes, 1999.

MACHADO, Álvaro Manuel. Dicionário de literatura portuguesa. Lisboa: Presença, 1996.

MATOS, Joaquim. Mário Cláudio: ficção e ideário. Porto: Caixotim, 2004.

MELO, João de. Antologia do conto português. Lisboa: Dom Quixote, 2005.

MORÃO, Paula. Viagens na terra das palavras. Lisboa: Cosmos, 1993.

MOSSE, George L. The image of man: the creation of modern masculinity. Nova York: Oxford University Press, 1996.

NOLASCO, Sócrates. O mito da masculinidade. Rio de Janeiro: Rocco, 1993.

REIS, Carlos. História crítica da Literatura Portuguesa. Lisboa: Editorial Verbo, 2006.

SANTOS, Roberto Corrêa. Para uma teoria da interpretação. Rio de Janeiro: Forense Universitária, 1989.

SEDGWICK, Eve Kosofsky. Between men: english literature and male homossocial desire. New York: Columbia University Press, 1985.

WINTER, Per; LOTHE, Jakob; SKEI, Hans. The art of brevity: excursions in short fiction theory and analysis. Columbia: University of South Carolina Press, 2004.

Recebido: 08 de janeiro de 2015

Aprovado: 02 de junho de 2015

Contato: foureaux24@yahoo.com 